\title{
DOPPLER LIDAR IN THE WIND FORECAST IMPROVEMENT PROJECTS
}

\author{
Yelena Pichugina ${ }^{1,2 *}$, Robert Banta ${ }^{2}$, Alan Brewer ${ }^{2}$, Aditya Choukulkar ${ }^{1,2}$, Melinda Marquis ${ }^{2}$, \\ Joe Olson ${ }^{1,2}$, and Mike Hardesty ${ }^{1,2}$ \\ ${ }^{l}$ Cooperative Institute for Research in Environmental Sciences, Boulder, CO \\ ${ }^{2}$ National Oceanic and Atmospheric Administration, Boulder, CO
}

\begin{abstract}
This paper will provide an overview of some projects in support of Wind Energy development involving Doppler lidar measurement of wind flow profiles. The high temporal and vertical resolution of these profiles allows the uncertainty of Numerical Weather Prediction models to be evaluated in forecasting dynamic processes and wind flow phenomena in the layer of rotor-blade operation.
\end{abstract}

\section{INTRODUCTION}

Intelligent development of wind-energy (WE) power plants requires high-quality measurements in the turbine rotor layer of the atmosphere to estimate the wind resources and understand meteorological processes controlling the Boundary Layer (BL) for the optimal design and operation of wind turbines, wind plants, and other components of the electrical grid. A potentially important tool in providing characteristics and behavior of the BL in response to various atmospheric conditions, stability, seasonality, and diurnal cycle is the numerical weather prediction (NWP) model, but without measurements in this layer for verification, the accuracy and fidelity of model output is unknown. To address the need for wind flow measurements at turbine-rotor heights, Doppler-lidar technologies are an attractive option. These technologies are aimed at providing cost effective data through the layer swept by modern turbine rotor blades at needed temporal and vertical resolutions. In recent years the number of research projects in WE involving lidars has significantly increased. Lidar measurements are used to study wind flow phenomena, including wake effects $[1,2]$ and Low Level Jets [3], and also for evaluating numerical model forecasting capabilities, and for finding ways to improve model skill and reduce the errors. Measurements from several offshore, ship-borne campaigns are available that use National Oceanic and Atmospheric Administration/Earth System Research Laboratory (NOAA/ESRL)'s High-Resolution Doppler Lidar (HRDL), which is a remote-sensing lidar system equipped with a motioncompensation system that has been shown to produce high-quality profile measurements [4]. Recently the HRDL dataset from a field campaign, the New England Air Quality Study (NEAQS-2004), designed to study air quality off the New England coast, was used to investigate properties of the flow in the rotor layer in the offshore environment, and to validate performance of NOAA NWP models.

\section{PREDICTION OF OFFSHORE WINDS}

The NOAA study to inform requirements for an observation network for WE, sponsored by the U.S. Department of Energy, was conducted in 2013. In the study, called the Position of Offshore Wind Energy Resources, or POWER, project, the unique measurements from ship-based lidar were used to verify NOAA NWP models and obtain information on key atmospheric phenomena that impact offshore wind forecasts. The verification of model skill in predicting hub-height winds over the ocean was performed by comparing hourly averaged lidar wind profiles to these produced by model. The model verification performed here is an evaluation of model skill in predicting hubheight winds over the ocean, using a total of 12 model configurations based on two modeling systems, the hourly-updated Rapid Refresh (RAP) system and a new hourly-updated version of North America Mesoscale (NAMRR) forecast system. The two models are run at both normal 
resolution ("parent" model) and at high-resolution ("nested" model) called High-Resolution Rapid Refresh or HRRR and NAMRR CONUS-Nest respectively. The short description of these models is given in Table 1 .

Table 1. Description of models used in the POWER study, horizontal grid resolution and NOAA facility running these models.

\begin{tabular}{|l|l|l|}
\hline \multicolumn{1}{|c|}{ Model } & Grid & Facility \\
\hline Rapid Refresh (RAP) & $13 \mathrm{~km}$ & OAR/ESRL \\
\hline $\begin{array}{l}\text { High Resolution Rapid } \\
\text { Refresh (HRRR) }\end{array}$ & $3 \mathrm{~km}$ & OAR/ESRL \\
\hline $\begin{array}{l}\text { North American } \\
\text { Mesoscale RR (NAMRR) }\end{array}$ & $12 \mathrm{~km}$ & NWS/NCEP \\
\hline $\begin{array}{l}\text { NAMRR Contiguous } \\
\text { United State (ConusNest) }\end{array}$ & $4 \mathrm{~km}$ & NWS/NCEP \\
\hline
\end{tabular}

Retrospective runs of all models were performed for two intensive measurement-modeling study periods of the POWER analysis, one week in July and one week in August 2004, selected to represent various wind-flow conditions as the research ship cruised around the Gulf of Maine. During both periods the research ship was covering a wide $241 \times 250 \mathrm{~km}(150 \times 155 \mathrm{mi})$ area as shown in Figure 1 (right panels). Examples of 15-min average wind profiles as time-height cross sections are given in Figure 1 (left panels) to illustrate the high vertical resolution of the data that allowed fast changing dynamic processes such as LLJs or sudden changes in wind speed or direction to be sampled.
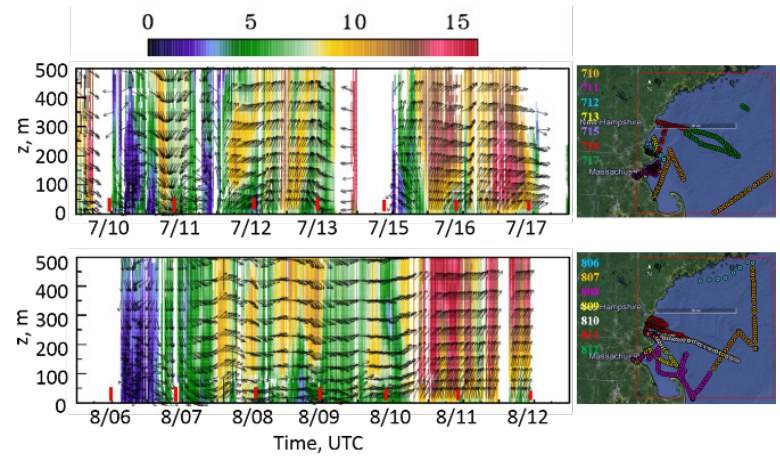

Figure 1. Left: Time-height cross sections of 15 -min averaged lidar-measured wind speed (color bar, scaled from 0 to $16 \mathrm{~ms}^{-1}$ ) and direction (arrows), computed from HRDL conical scans during two intensive measurement-modeling study periods of the POWER analysis (top: July period, bottom: August period).
Vertical axis is height above sea level (m), and horizontal axis is time in UTC. Right: Google maps illustrating color coded ship tracks for each day during selected periods in (top) July and (bottom) August.

Due to the heavy rain and dense fog observed from the evening of 13 July until mid-afternoon of 15 July, HRDL was not operated during these hours and measurement hours during several other days were also shortened by synoptic conditions (blank area on the left panels). For comparison with modeled winds, lidar data were averaged over 1-hr intervals and interpolated to the model heights. A visual overview of time-height cross sections of the HRDL-measured wind-speed data and model-initialization data shows that the overall features and trends are represented in the models. However, a quantitative analysis showed differences in flow strength and timing between modeled and observed wind profiles. Sample comparisons of (black lines) measured and (color lines) modeled wind profiles for the initialization time are shown in Figure 2 to illustrate the general findings. The largest discrepancies were observed for stronger winds and LLJ-like profiles, which are more frequent during nighttime hours as demonstrated in the top four profiles of 16 July.

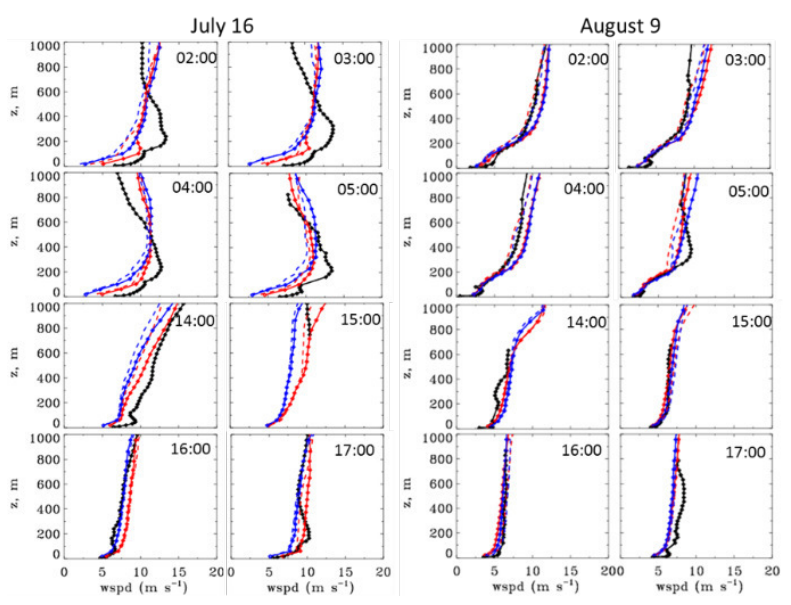

Figure 2. Examples of lidar-measured and modeled wind profiles (left two columns) July 16; (right two columns) August 9. Lidar profiles are shown in black. Red and blue lines show profiles modeled by NAMRR model in parent (NAMRR) and nested (NAMRR ConusNest) modes correspondently. Solid and dashed lines indicate model runs with different sets of data assimilated into model. Discussion of the difference of the assimilated sets of data and its impact on the results of the comparisons is beyond the scope of this paper. 
Overall, better agreement was observed for weak and moderate wind speeds as shown in all profiles for 9 August. Similar results were observed for all days in both study periods showing larger discrepancies below $200 \mathrm{~m}$, for stronger $\left(>10 \mathrm{~ms}^{-}\right.$ $\left.{ }^{1}\right)$ winds, and in the presence of LLJ events in period-averaged comparisons of wind profiles. Figure 3 shows mean error statistics for each study period.

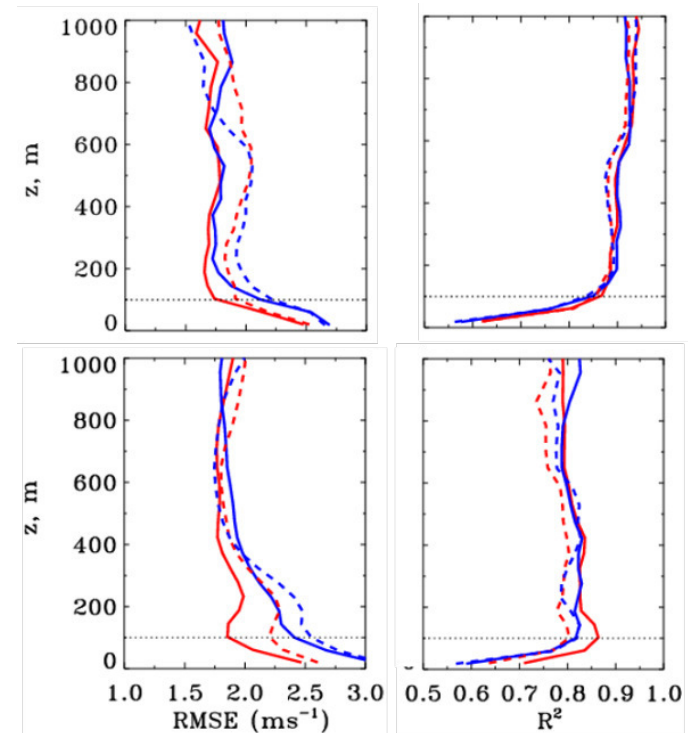

Figure 3. Profiles of the Root-mean Square error (RMSE) and correlation coefficients $\left(\mathrm{R}^{2}\right)$ between observed and initial-condition model wind speed averaged over (top) August and (bottom) July study periods. Red lines on all panels are for NAMRRCONUS and blue lines are for NAMRR parent mode of the model runs. Solid and dashed lines are for different sets of data assimilated into each model as described in Figure 2.

HRDL wind data were used to verify model forecasts out to $12 \mathrm{~h}$ lead time. To test model performance, HRDL data were averaged over the layer from 20 to $500 \mathrm{~m}$ ASL. Figure 4 shows the RMSE for the eight model configuration runs for the August period. Overall, a quantitative statistical assessment of the mean-wind accuracy of the models showed the RMSE between observed and modeled winds of $2-2.5 \mathrm{~m} / \mathrm{s}$ for the first 2-3 lead hours, increasing for the later forecast hours. Such errors could be explained partially by the use of an archive dataset from an experiment that was designed to trace plume dispersion over the water surface (www.esrl.noaa.gov/csd/ICARTT/.1), and these objectives are different from model validation purposes. Another part of the error could be induced by the using older versions of models in the study and the availability of historical datasets to assimilate into the retrospective model runs. The overall results from the POWER project demonstrated the importance of observational data

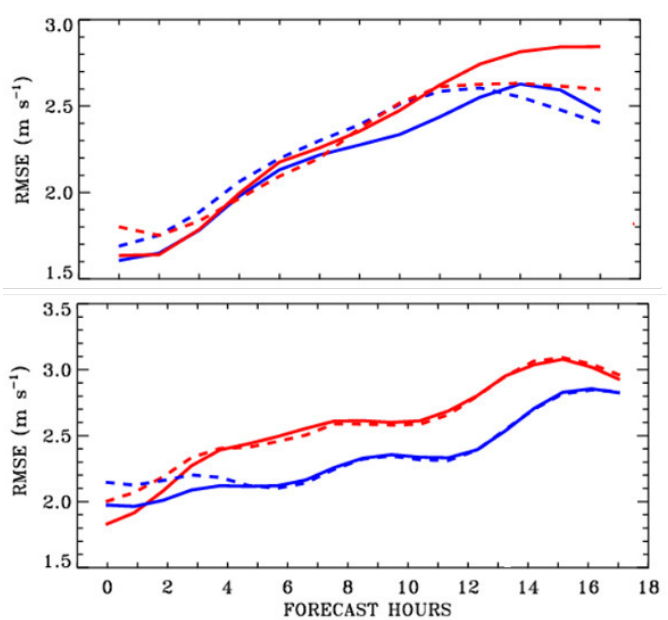

Figure 4. RMSE between observed and modeled wind in August 6-12 for data averaged over 20-500m layer. Top panel: (red) HRRR and (blue) RAP models. Bottom panel: (red) NAMRR ConusNest and (blue) NAMRR models. Solid and dashed lines are for different sets of data assimilated into each model as described in Fig. 2.

to validate NWP models, and to determine the uncertainty of wind resource assessment in one of the US offshore areas projected for wind plant development. Comparisons of model ability to simulate diurnal cycles, strong and weak winds, LLJ-like profiles, and other time- and spacedependent features of the flow, indicated areas of most needed model improvement. These areas will also be of primary interest for the validation and improvement of model skill in prediction of the wind flow over a complex terrain.

\section{WIND FORECAST IMPROVEMENT PROJECT (WFIP II)}

The WFIP-II, aimed at developing a better understanding of the factors that shape wind flow over complex terrain, will be conducted in the Columbia River Gorge area near the border of Oregon and Washington states, east of the Cascade Mountains. The project, sponsored by the Department of Energy, is a collaborative effort to improve model performance in predicting wind 
flow and BL phenomena in the mountain region occupied by numerous wind farms. The main objectives of this experiment are to characterize complex terrain atmospheric phenomena that impact model accuracy and to validate and improve weather prediction models, including the NOAA HRRR operational model and other, finer scale models such as WRF or LES. Participating organizations will deploy a variety of instruments in the study area for an 18-month period to provide real-time measurements including several scanning and wind-profiling lidars. Two NOAA scanning Doppler lidars, obtained commercially and updated for remote operation and data acquisition to better fit project objectives, will also operate for the duration of the experiment. Two proposed sites, in the vicinity of Wasco and Arlington airports (Figure 5), were selected for possible location of these instruments. These lidars will either be operating from each site, providing profiles of wind flow parameters, or will operate from one (Wasco) site in the DualDoppler scanning mode providing measurements of turbulence as well as mean-wind profiles. I either case lidar data will be used for the comparison with model output.

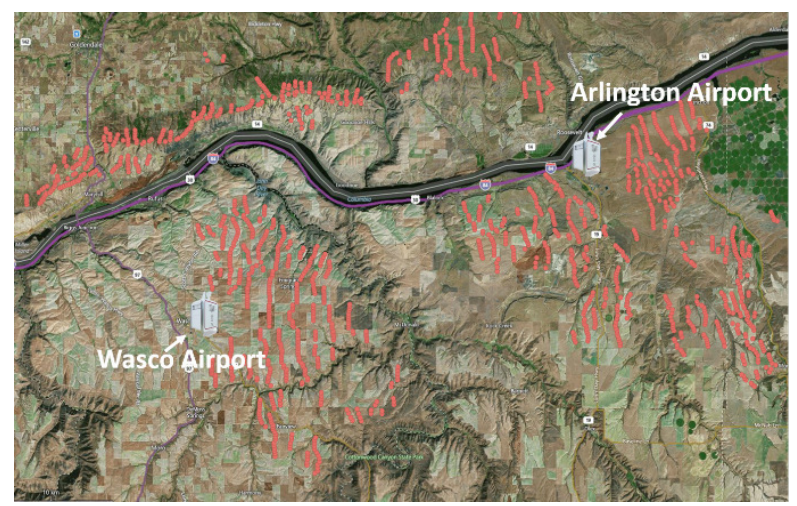

Figure 5. The USGS animated map shows proposed locations for the NOAA scanning Doppler lidars. Red dots on the map indicate wind turbines.

WFIP-II will take advantage of the results from two prior field programs designed to test the uncertainty of measurements from various types of lidar, and their coordinated scanning strategies. Both of these short-term experiments were conducted at Erie, Colorado. One of the experiment, called the Lidar Uncertainty Measurement EXperiment (LUMEX) was executed in in the summer of 2014 and another, called the EXperimental Measurement Campaign for Planetary Boundary Layer Instrument Assessment (XPIA) was executed in the spring of 2015. An overview these experiments will be presented at this conference by Brewer et al. (2015) and Choukulkar et al. (2015).

\section{CONCLUSIONS}

The offshore Doppler lidar dataset allowed detailed

verification of NWP model output in the atmospheric layer, occupied by turbine rotors. The scientific and measuring capabilities of the WFIPII project, represented by the collaborating organizations, will allow an unprecedented characterization of the key atmospheric processes in complex terrain leading to the better $\mathrm{BL}$ parametrization and improved wind flow forecasts.

\section{ACKNOWLEDGEMENT}

The POWER and WFIP-II projects are sponsored by the U.S. Department of Energy (DOE), Energy Efficiency and Renewable Energy office, Wind and Water Power program. We want to thank all our colleagues for the collaboration and their tremendous contribution during the POWER project and in the preparation of the forthcoming WFIP-II project: Stan Benjamin, Eric James, and Jaymes Kenyon - all from the NOAA/ ESRL Global Science Division; James Wilczak, Laura Bianco and Irina Djalalova - all from the NOAA/ ESRL Physical Science Division Jacob Carley and Geoff DiMego from the NOAA National Weather Service (NWS). We also want to thank Joel Cline from DOE for the leadership in preparation of both projects; management, execution and reporting results from the POWER project.

\section{REFERENCES}

[1] Aitken, M.L., J.K. Lundquist, R.M. Banta, and Y.L. Pichugina, 2014: Quantifying wind turbine wake characteristics from scanning remote sensor data. $J$. Atmos. Ocean. Technol., 31, 765-787.

[2] Pichugina Y.L., R. M. Banta, W.A. Brewer, J.K. Lundquist, R. M. Hardesty, M.L. Aitken, R.J. Alvarez, S.P. Sandberg, A M. Weickmann N.D. Kelley, and J.D. Mirocha, 2012: Estimation of wind turbine wake characteristics from Doppler lidar measurements, $26^{\text {th }}$ ILRC, Proceedings, 4pp 
[3] Banta, R.M., Y.L. Pichugina, N.D. Kelley, R.M. Hardesty, W.A. Brewer, (2013): Wind energy meteorology: Insight into wind properties in the turbine-rotor layer of the atmosphere from high resolution Doppler lidar. Bulletin of the American Meteorological Society, 94, 6, 883-902.

[4] Pichugina, Y.L., R. M. Banta, W. A. Brewer, S. P. Sandberg, and R. M. Hardesty, 2012: Doppler-lidarbased wind-profile measurement system for offshore wind-energy and other marine-boundary-layer applications. J. Appl. Meteor. Climatol. 51, 8, pp 327349. 